\title{
CADUCIDAD DE LA ACCIÓN CONTRACTUAL CUANDO LA LIQUIDACIÓN DEL CONTRATO ES POSTERIOR A LA OPORTUNIDAD LEGAL"
}

\author{
Expiration of the action of \\ contractual disputes when the contract \\ is settled after the legal term
}

Nicolás Enrique Martínez Benavides***

\begin{abstract}
Resumen
Este artículo estudia la caducidad de la acción de controversias contractuales cuando el contrato es liquidado por fuera de las oportunidades legales para su adopción bilateral o unilateral. El estudio inicia con un análisis de las posiciones encontradas al interior de la Sección Tercera del Consejo de Estado respecto al objeto de estudio. Posteriormente, el artículo finaliza señalando que una eventual unificación jurisprudencial debería acoger la tesis que contabiliza el término de caducidad a partir de la ejecutoria del acto de liquidación. Esto debido a que es una tesis garantista de los derechos de acceso a la administración de justicia e igualdad, y porque la tesis contraria desborda el ámbito de aplicación de la norma.
\end{abstract}

Palabras clave: Caducidad de la acción contractual, acto de liquidación, acceso a la administración de justicia, derecho a la igualdad.

* Artículo inédito.

Para citar el artículo: MARTÍNEZ BENAVIDES, Nicolás Enrique. Caducidad de la acción contractual cuando la liquidación del contrato es posterior a la oportunidad legal. Revista del Instituto Colombiano de Derecho Procesal. No. 47 Enero - Junio. 2018, pp. 167-192.

Recibido: 08 de marzo de 2018 - Aprobado: 28 de julio de 2018.

* Magister en derecho con énfasis en responsabilidad contractual y extracontractual civil y del Estado de la Universidad Externado de Colombia, Bogotá, Colombia. Abogado de la Universidad Externado de Colombia, Bogotá, Colombia. 
Caducidad de la acción contractual

\begin{abstract}
The paper studies the expiration of the action of contractual disputes when the contract is settled outside the legal term for the bilateral or unilateral adoption of the settlement. The author discusses the different theories developed within the Third Section of the Council of State regarding the interpretation of the expiration of the action in such cases. Subsequently, the author argues that by means of unification of jurisprudence, the Council of State should accept the thesis under which the calculation of the term of expiration of the action should be counted from the execution date of the act of settlement, because it is a thesis that protects the access to the administration of justice and right to equality, and also due to excess in the scope of application of the contrary thesis.
\end{abstract}

Keywords: expiration of the action of contractual disputes, contract settlement, access to the administration of justice, right to equality.

\title{
Introducción
}

"Donde hay dos abogados, hay tres interpretaciones" así señala el famoso adagio para exponer, de forma jocosa, las diferentes soluciones que puede tener un problema jurídico bajo la lupa de varios juristas.

No obstante, la jocosidad se transforma en preocupación cuando las diversas interpretaciones surgen al interior de un tribunal de cierre, debido a que afecta la igualdad de quienes acuden a la jurisdicción y desorienta a los jueces de menor jerarquía respecto del precedente judicial a seguir.

En búsqueda de una solución al problema de la congestión judicial al interior de la Sección Tercera del Consejo de Estado, la Sala Plena de la Corporación expidió el Acuerdo 140 del 23 de noviembre de 2010, modificatorio del Acuerdo 58 de 1999 -reglamento interno del Consejo de Estado-, mediante el cual dividió la Sección Tercera en tres subsecciones (A, B y C), cada una integrada por tres magistrados,

Pese a la finalidad loable de la subdivisión, en la práctica ha permitido que se presenten fallos contradictorios al interior de la Sección Tercera del Consejo de Estado. En efecto, en la actualidad coexisten dos interpretaciones respecto al conteo de la caducidad de la acción de controversias contractuales cuando el acto de liquidación del contrato se profiere con posterioridad a las oportunidades legales para ello.

En el presente artículo se estudiarán en primer lugar los aspectos generales sobre la caducidad de la acción de controversias contractuales, los cuales son 
necesarios para darle alcance al problema de la coexistencia de dos tesis jurisprudenciales contrapuestas. Posteriormente, se plantearán las dos posiciones jurisprudenciales: una que contabiliza la caducidad de la acción a partir del fenecimiento de los plazos para la liquidación bilateral y unilateral; y otra que lo hace desde cuando se firma el acta o queda en firme el acto, pese a que sea con posterioridad al fenecimiento de las oportunidades legales.

El análisis de la controversia de la mano de principios como el de interpretación pro homine e igualdad, además de un estudio crítico de la primera postura esbozada, permitirán finalmente otorgar argumentos para que, en un eventual escenario de unificación jurisprudencial, la Sección Tercera acoja la segunda tesis.

\section{Aspectos previos}

Con el fin de darle alcance al problema jurídico a plantear y a las posiciones jurisprudenciales en torno al mismo, se hace necesario responder previamente los siguientes interrogantes: i) ¿Cuáles son las oportunidades legales para la liquidación bilateral y unilateral de los contratos estatales? ii) ¿Cuál es el término de caducidad de la acción de controversias contractuales?

Plazos legales para liquidar un contrato estatal

La liquidación de los contratos estatales es un procedimiento que tiene por objetivo finiquitar la relación contractual: las partes se pronuncian respecto del cumplimiento o incumplimiento de las prestaciones y en general sobre cualquier vicisitud en la ejecución del contrato ${ }^{1}$.

El Decreto 222 de 1983 señalaba los casos en los cuales procedía la liquidación (art. 287) y el contenido del acta (art. 289), pero no indicó la oportunidad para dicho trámite. La normatividad solamente indicaba que "si no hubiere acuerdo para liquidar un contrato, se tendrá por firme la liquidación presentada por la entidad contratante", de lo cual se dedujo que existían dos clases de liquidación: la bilateral o de común acuerdo y la unilateral por la administración en caso de que la primera fallase.

La Jurisprudencia del Consejo de Estado suplió el vacío legal y señaló que el "término plausible" para liquidar de manera bilateral un contrato eran 4 meses, dentro de los que se incluían dos meses para que el contratista aportara la documentación y dos más para el trabajo de liquidación bilateral ${ }^{2}$.

1 HERNÁNDEZ, Aida Patricia. La liquidación del contrato estatal, Revista digital de derecho administrativo $N^{\circ}$ 1, Bogotá, Universidad Externado de Colombia, 2009, p. 1.

2 Consejo de Estado, Sala de lo Contencioso Administrativo, Sección Tercera, sentencia del 10 de septiembre de 1987, exp. 3711. 
Adicionalmente señaló que una vez fenecido el término de liquidación bilateral sin acuerdo, la administración contaba con un plazo adicional de dos meses para liquidar el contrato de forma unilateral ${ }^{3}$.

Los anteriores criterios jurisprudenciales fueron posteriormente adoptados por el legislador. En primer lugar, en el artículo 60 de la Ley 80 de 1993 donde se fijó como término para la liquidación bilateral del contrato el lapso de 4 meses luego de su terminación, salvo que en el pliego de condiciones o en el contrato mismo se pactara otro término.

Finalmente se consagró el lapso de 2 meses para la liquidación unilateral, luego de fenecida la oportunidad para la liquidación bilateral, en los artículos 44 de la Ley 446 de 1998, 11 de la Ley 1150 y 164 de la Ley 1437 de 2011, normas en las cuales se reiteró el término de 4 meses iniciales para la liquidación bilateral.

\subsection{Término de caducidad de la acción contractual}

La caducidad es el fenómeno procesal "que le impide al juez conocer una controversia propuesta, que fue formulada luego de transcurrido un plazo señalado por la ley para esos efectos. Se trata de un fenómeno extintivo en la medida en que le cierra la posibilidad al demandante para que la autoridad jurisdiccional defina sus pretensiones"4.

En relación con el término para el ejercicio de la acción de controversias contractuales, las normas que regularon la caducidad de la misma en vigencia del Código Contencioso Administrativo (Decreto 01 de 1984), esto es, el artículo 136 original, el Decreto extraordinario 2304 de 1989 y el artículo 44 de la Ley 446 de 1998; al igual que en la regulación del artículo 164 del actual Código de Procedimiento Administrativo y de lo Contencioso Administrativo (Ley 1437 de 2011), han mantenido el criterio según el cual la acción caduca en un término de dos años.

3 "A falta de acuerdo, estima la Sala que la entidad contratante debe proceder a la liquidación unilateral dentro de los dos meses siguientes al vencimiento del término para hacer la liquidación de común acuerdo. Aunque este nuevo plazo no está previsto por la ley de manera específica, coincide con el consagrado legalmente para que se produzca el fenómeno del silencio administrativo negativo (Decreto Ley 2.304 de 1989 , arts. $1^{\circ} \mathrm{y}^{\circ}$ ) y, por esta razón, lo adopta la Sala para eventos como el que aquí se presenta": Consejo de Estado, sentencia del 11 de diciembre de 1989, citada a su vez en Consejo de Estado, Sala de lo Contencioso Administrativo, Sección Tercera, sentencia del 22 de junio del 2000, exp. 12723.

4 GALINDO VACHA, Juan Carlos. Lecciones de derecho procesal administrativo, Vol 2, Bogotá, Pontificia Universidad Javeriana, 2006, p. 225. 
Sobre el particular únicamente se presentó discusión en torno a la interpretación del artículo 55 de la Ley 80 de $1993^{5}$, el cual establece un término de prescripción de 20 años de las acciones derivadas de los artículos 50 a 53 del mismo cuerpo normativo.

No obstante esta discusión, y pese a que en algunas providencias se acogió el término de 20 años para la caducidad de la acción, lo cierto es que en relación con la acción contractual dirigida a atacar la validez de actos contractuales, siendo uno de estos el de liquidación, el término de caducidad siempre se entendió de 2 años ${ }^{6}$. Esto, pues el término del artículo 55 de la Ley 80 de 1993 se circunscribió

5 “Con la Ley 80 de 1993 se generó alguna confusión en el manejo de la caducidad, pues se estableció como regla que todos los actos y los hechos de la operación administrativa contractual, incluidos los previos o separables, se someterían a la acción contractual, con excepción del acto de adjudicación, del que declara desierta la licitación y del que resuelve la impugnación de la inscripción de un proponente en la Cámara de Comercio, que se someten a la acción de nulidad y restablecimiento del derecho con una caducidad de cuatro meses. Pero además se habló de las acciones derivadas de la responsabilidad de quienes con sus actos u omisiones antijurídicas causaban daño a las partes del contrato, según los artículos 50 a 53 de la Ley 80 de 1993, la cual tendrá una prescripción de 20 años. Tales disposiciones llevaron a algunos a pensar que la caducidad de la acción contractual había sido modificada, interpretación que no era cierta, pues la ley dejó la acción contractual en la forma prevista sin ninguna variación. Lo nuevo allí era la prescripción frente a los actos, hechos o las omisiones antijurídicas que, por el realce que la nueva constitución y la ley le daban a la responsabilidad de los que intervienen en la contratación, había quedado fijada en veinte (20) año. El exigir, entonces, cualquiera de las pretensiones derivadas del contrato, como la responsabilidad derivada de su incumplimiento, tiene, en todo caso, una caducidad de dos años": PALACIO HINCAPÍE, Juan Ángel. Derecho procesal administrativo, 9. a ed., Bogotá, Librería Jurídica Sánchez R Ltda, 2017, p. 296.

6 "Luego, con la entrada en vigencia del decreto Ley 2304 de 1989, que reformó el decreto Ley 01 de 1984 (C. C. A), el término de caducidad mencionado el decreto lo mantuvo en los dos años dispuestos por el decreto Ley 01 de 1984, "de ocurridos los motivos de hecho o de derecho que le sirvan de fundamento" (art. 23 que modificó art. 136 C.C.A.). Posteriormente la Ley 80 de 1993 modificó el plazo legal de dos años, que estaba previsto en el artículo 136 numeral 6 del C. C. A, para promover la acción de controversias contractuales sólo respecto de las omisiones de los contratantes y de las conductas antijurídicas de éstas. En efecto, el legislador amplió el término de prescripción de la acción a veinte años para los eventos de las conductas antijurídicas contractuales. De esta manera Administración y contratista, bajo la vigencia de esa norma, podían perseguirse judicialmente dentro de un término de veinte años, cuando sus conductas (activas u omisivas) eran antijurídicas, etc. (consultores, servidores públicos etc). Sin embargo, el cuestionamiento judicial de la validez de los actos jurídicos contractuales, que se presumen válidos (contrato, actos bilaterales, actos unilaterales de la administración y del particular) y de otras conductas jurídicas (hecho del príncipe) no imputables a las partes cocontratantes (hechos imprevisibles), debían hacerse dentro del término original de caducidad de dos años (art. 136 inc. 6o. C. C. A). Posteriormente la Ley 446 de 1998 unificó en dos años, por regla general, el término de caducidad de las acciones contrac- 
a demandas referidas a la responsabilidad patrimonial derivadas del incumplimiento del contrato por las partes o la civil de los servidores públicos ${ }^{7}$.

En suma, el término de caducidad de la acción contractual es de dos años, sin que se analice todavía desde qué momento deben empezar a contabilizarse los mismos, cuando la liquidación es posterior a las oportunidades legales. Esta disyuntiva, es precisamente el objeto del presente trabajo.

\section{Planteamiento del problema}

La discusión sobre la que gira el presente escrito surge del interrogante: ¿Desde cuándo empieza el término de caducidad de la acción de controversias contractuales si la liquidación del contrato se realiza luego de las oportunidades legales para liquidarlo bilateral y unilateralmente?

Se parte del supuesto de que con posterioridad a los términos arriba señalados -cuatro meses de liquidación bilateral (o el que las partes convengan) + dos meses de liquidación unilateral- el contrato se liquida de común acuerdo o de forma unilateral por la administración, posibilidad actualmente consagrada en el artículo 11 de la Ley 1150 de $2007^{\circ}$. Así las cosas, se pasarán a analizar las posiciones jurisprudenciales que responden el interrogante expuesto.

\subsection{Primera postura: el término inicia al fenecer las oportunidades para su liquidación bilateral y unilateral}

Según esta posición el término de dos años de caducidad inicia luego de fenecido el plazo convencional para liquidarlo bilateralmente o en su defecto el de cuatro meses señalado en la ley más los dos meses para que la administración lo liquide unilateralmente, sin que sea relevante que con posterioridad a dichos lapsos el contrato sea liquidado.

Esta tesis es respaldada por la Subsección C de la Sección Tercera del Consejo de Estado y como sentencia hito de la línea jurisprudencial, se puede identificar la providencia del 30 de enero de 2013, en la cual se expresa:

tuales": Consejo de Estado, Sala de lo Contencioso Administrativo, Sección Tercera, auto del 19 de febrero de 2004, exp. No. 24427.

7 Consejo de Estado, Sala de lo Contencioso Administrativo, Sección Tercera, sentencia de julio 22 de 2009, exp. No. 17552.

8 Para quien desee profundizar sobre el tema relativo a la competencia para liquidar el contrato estatal puede consultar: EXPÓSITO VELEZ, Juan Carlos. La liquidación bilateral de los contratos estatales: un mecanismo alternativo de solución de conflictos. Revista digital de derecho administrativo N 1, Bogotá, Universidad Externado de Colombia, 2009. 
Con otras palabras, habiendo terminado el contrato el 29 de noviembre de 1996, los cuatro (4) meses que siguen vencieron el 29 de marzo de 1997, los dos (2) meses subsiguientes culminaron el 29 de mayo de 1997, y la caducidad de dos (2) años se consolidó el 29 de mayo de 1999.

Si la demanda se presentó el 12 de abril de 2000 es evidente que la caducidad ya había operado puesto que, como ya se dijo, la liquidación extemporánea ninguna incidencia tiene en el término de caducidad ya que este empezó a correr de manera irremediable desde que concluyeron los plazos legales para realizarla9 . (énfasis del autor)

Esta posición se fundamenta en la importancia del instituto de la caducidad dentro del ordenamiento jurídico y la perentoriedad de los términos que la ley establece al respecto. Por ende, considera que la caducidad debe contarse desde el fenecimiento de dichos lapsos (4+2), pues de no ser así la misma dependería de las partes.

En la sentencia en cita se lee:

Por consiguiente si, cuando es menester la liquidación del contrato, hay un plazo legalmente señalado para realizarla, bien sea de común acuerdo o bien sea de manera unilateral, y si la caducidad de la acción contractual empieza a correr a partir de la respectiva liquidación, es conclusión obligada que si el plazo legalmente previsto para realizar la liquidación concluye sin que esta se hubiere hecho, irremediablemente el término de caducidad habrá empezado a correr a partir de la conclusión de este último momento y por ende ninguna incidencia tendrá en el término de caducidad una liquidación posterior.

Sostener lo contrario sería tanto como argumentar que el término de caducidad puede quedar al arbitrio de alguna de las partes.

(...)

Y es que la posición que aquí se critica impondría la obligada pero errada e ilegal conclusión consistente en que el término de caducidad ya no sería de dos años contados a partir del momento en que vencieron los términos legales para liquidar el contrato, sino de treinta y tres o más meses (13 o más desde el vencimiento de los términos legales para liquidar el contrato y 24 más a partir de la liquidación extemporánea), todo por decisión de quien o quienes liquidaron el contrato por fuera de los términos legalmente previstos para ello".

Dentro del desarrollo de esta línea jurisprudencial la misma tuvo una ligera variante. Se aclaró que si el acto de liquidación se expide cuando ya está

9 Consejo de Estado, Sala de lo Contencioso Administrativo, Sección Tercera, Subsección C, sentencia del 30 de enero de 2013, exp. 23.136. 
caducada la acción contractual, es decir con posterioridad a los dos años luego de los respectivos cuatro meses de liquidación bilateral y dos meses de liquidación unilateral, la acción a ejercer no es la contractual sino la de nulidad y restablecimiento del derecho que caduca en cuatro meses.

C:

Sobre este punto en Sentencia del 12 de junio de 2014 indicó la Subsección

Cabría preguntarse entonces, si el término de caducidad de la acción contractual ya ha operado y la administración profiere un acto administrativo, como por ejemplo una liquidación unilateral del contrato, ¿Qué acción puede promoverse para cuestionarlo?

Indudablemente no es la acción contractual porque ésta se ha extinguido en virtud de la caducidad pero como quiera que se ha proferido un acto administrativo ilegal, ya que modifica los términos creados por el legislador o revive los que de acuerdo con la ley se han extinguido, y que ningún acto de la administración puede quedar sin control, pues de lo contrario se vulneraría el derecho al acceso a la justicia, es conclusión obligada que el camino en este caso es la acción de nulidad y restablecimiento del derecho ${ }^{10}$.

Este último criterio ha sido reiterado en otras providencias de la Subsección, en las cuales se declaró la ineptitud sustantiva de la demanda respecto de acciones contractuales formuladas con posterioridad a los dos años de caducidad, subsiguientes a los seis meses iniciales (cuatro meses de liquidación bilateral + dos meses de liquidación unilateral $)^{11}$.

De forma gráfica la línea jurisprudencial dispone lo siguiente:

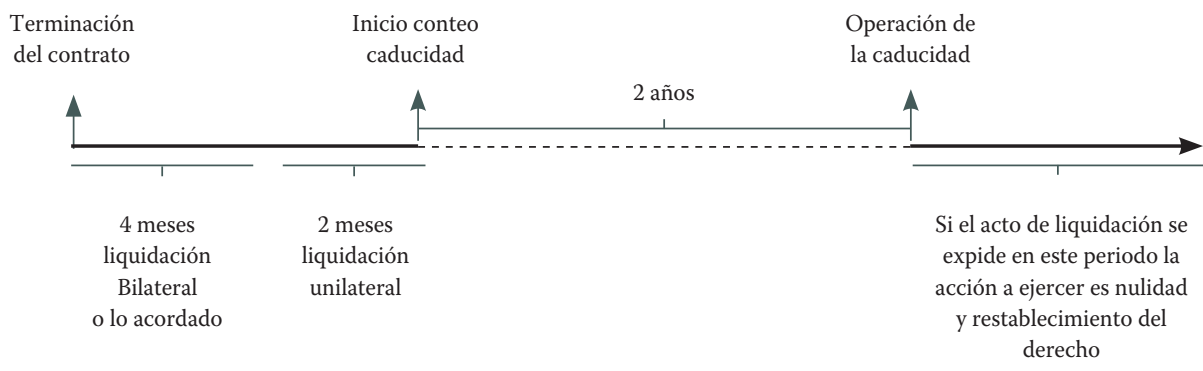

10 Consejo de Estado, Sala de lo Contencioso Administrativo, Sección Tercera. Subsección C, sentencia del 12 de junio de 2014, exp. 29.469.

11 Consejo de Estado, Sala de lo Contencioso Administrativo, Sección Tercera. Subsección C, sentencia del 29 de abril de 2015, exp. 34836

174 Revista del Instituto Colombiano de Derecho Procesal • No. 47 
Las tesis que sustentan esta línea jurisprudencial, han sido reiteradas en diversas providencias ${ }^{12} y$, pese al cambio de composición de la Subsección en los últimos años, actualmente se encuentra consolidada al ser apoyada por los tres Consejeros que integran la Subsección como se puede observar en las sentencias del $1^{\circ}$ de abril de $2016^{13}$ y 18 de mayo de $2017^{14}$.

\subsection{Segunda postura: el término depende del acto de liquidación}

Esta postura, opuesta a la primera, indica que el término de caducidad de dos años corre a partir de la firma del acta o desde la ejecutoria del acto de liquidación, inclusive si este se suscribe o expide con posterioridad a los lapsos convencionales o legales para la liquidación bilateral (cuatro meses) y unilateral (dos meses).

De forma ilustrativa, se plantea:

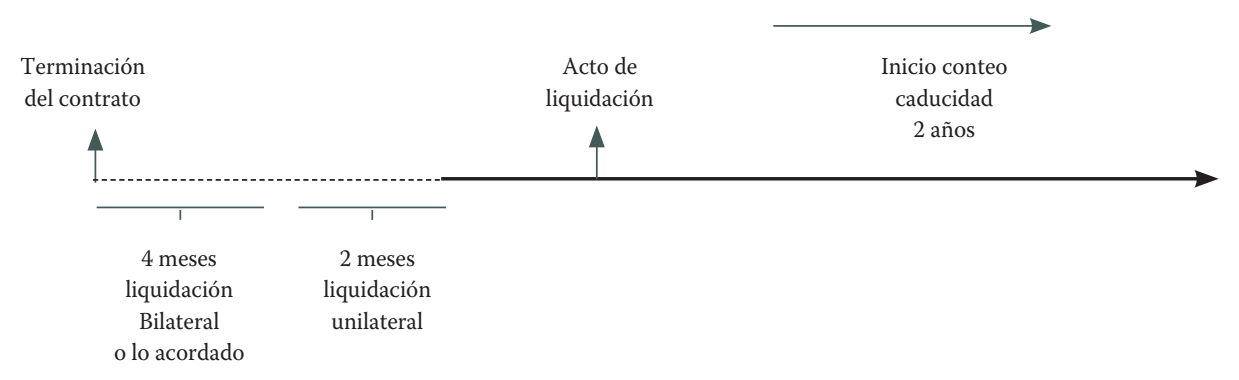

Dentro de esta postura se pueden identificar providencias de las otras subsecciones de la Sección Tercera como lo son el auto del 15 de septiembre de 2011 de la Subsección $\mathrm{A}^{15}$, o la sentencia del 20 de febrero de 2014 de la Subsección B ${ }^{16}$.

12 Entre otras: Consejo de Estado, Sala de lo Contencioso Administrativo, Sección Tercera, Subsección C, sentencia del 24 de julio de 2013, exp. 28.768; Consejo de Estado, Sala de lo Contencioso Administrativo, Sección Tercera, Subsección C, sentencia del 16 de marzo de 2015, exp. 32797; Consejo de Estado, Sala de lo Contencioso Administrativo, Sección Tercera, Subsección C, sentencia del 15 de octubre de 2015, exp. 48.656.

13 Consejo de Estado, Sala de lo Contencioso Administrativo, Sección Tercera, Subsección C, sentencia del $1^{\circ}$ de abril de 2016, exp. 50.128. Sentencia suscrita por los consejeros Jaime Orlando Santofimio Gamboa y Guillermo Sánchez Luque.

14 Consejo de Estado, Sala de lo Contencioso Administrativo, Sección Tercera, Subsección C, sentencia del 18 de mayo de 2017. exp. 57864. Sentencia suscrita por los consejeros Jaime Orlando Santofimio Gamboa y Jaime Enrique Rodríguez Navas.

15 Consejo de Estado, Sala de lo Contencioso Administrativo, Sección Tercera, Subsección A, auto del 15 de septiembre de 2011, exp. 41154.

16 Consejo de Estado, Sala de lo Contencioso Administrativo, Sección Tercera, Subsección B, sentencia del 20 de febrero de 2014, exp. 28206. 
En la primera de las providencias se señala:

"Así entonces, en cuanto a la primera de las pretensiones se refiere, según resulta de lo pactado en la cláusula novena del contrato y de lo consignado en el acto administrativo demandado, la liquidación unilateral del mismo se llevó a cabo después de transcurridos aproximadamente 7 años desde su terminación, lo que de suyo supone, independientemente de que el contrato haya debido o no liquidarse y del término en el que ello ha debido hacerse, que existe un acto administrativo que se encuentra revestido de la presunción de legalidad y que, por lo tanto, tiene plena fuerza ejecutoria y ejecutante.

De acuerdo con lo que acaba de expresarse, la caducidad de la acción respecto de esta pretensión debe empezar su conteo, de conformidad con lo dispuesto en literal $d$ ) del numeral 10 del artículo 136 del Código Contencioso Administrativo y tal como lo señaló la Corporación en la providencia citada, a partir de la ejecutoria del acto administrativo que liquidó unilateralmente el contrato, independientemente de haberse expedido por fuera de los términos dispuestos legalmente para ello, entender lo contrario sería tanto como eliminar para la parte que con él se considera afectada la posibilidad de atacarlo en vía judicial y, por contera, dejarlo incólume ante cualquier control de este tipo". (énfasis del autor)

Igualmente el ex-Consejero de Estado Enrique Gil Botero no acompañó la tesis de la Subsección C, y en su disidencia razonó:

"[...] cómo se cuenta el plazo de caducidad de la acción contractual cuando éste ya está corriendo, pero no obstante la administración dicta un acto administrativo -como en el caso concreto- en el interregno. En esta hipótesis se presentan dos situaciones procesales extremas, que dan lugar a soluciones diversas: i) de un lado, que el acto se dicte muy cerca al inicio del cómputo de la caducidad - por ejemplo, pasado un mes- o, ii) de otro lado, que se dicte muy cerca del vencimiento de ese plazo - por ejemplo, el último día del segundo año-.

De atenerse al primer supuesto, parece posible sostener que la caducidad para demandar ese acto administrativo -o cualquier otro aspecto de inconformidad con el contrato-, es lo que resta -23 meses- del término de caducidad que ya corre, hasta completar los dos años. Pero si con esta misma tesis se resuelve el segundo supuesto la problemática se complica demasiado, porque en la práctica la administración quedaría sin control judicial, pues una decisión que se dicta el último día de la caducidad hace imposible su control judicial, ya que materialmente el afectado no tendrá la oportunidad real de ejercer su derecho de acceso a la administración de justicia: ¿acaso en un día se puede preparar y presentar una demanda? 
Admitir semejante posibilidad conduciría al abuso por parte de la administración y a la desviación de su poder, porque quedaría autorizada para expedir actos administrativos -así careciera de competencia, o contemple cualquier otro vicio- hasta el día en que caduca la acción contractual, con la seguridad de que el afectado no tendrá la oportunidad material de cuestionar la legalidad de la decisión que lo afecta.

El anterior supuesto condujo a la Corporación a señalar que, en eventos como este, la caducidad de la acción contractual se cuenta desde la ejecutoria de la decisión, y de manera independiente, de modo que se garantice el derecho de acceso a la administración de justicia y, sobre todo, el derecho a controlar las decisiones del Estado ${ }^{17}$.

Esta postura permite el estudio de la pretensión contra el acto de liquidación si la demanda se interpuso dentro de los dos años siguientes a su ejecutoria, sin importar que haya sido expedido por fuera de las oportunidades para su adopción bilateral o unilateral $(4+2)$. Además, se aclara que el estudio de la pretensión contra el acto de liquidación no revive la caducidad de otras pretensiones.

\section{Análisis de las posiciones jurisprudenciales}

Como se observa el tema no es pacífico al interior de la Sección Tercera del Consejo de Estado, y dado que las subsecciones tienen posiciones diversas sobre un mismo punto de derecho, se cumple uno de los requisitos para la unificación jurisprudencial, acorde a lo regulado en el Acuerdo 140 de $2010^{18}$.

En un eventual escenario de unificación de jurisprudencia, la Sección Tercera debería inclinarse por la segunda de las posturas presentadas, esto es, aquella que contabiliza la caducidad desde que efectivamente se firma el acta, en caso de liquidación bilateral, o desde la ejecutoria del acto de liquidación, cuando es adoptado unilateralmente, por las razones que pasan a exponerse.

17 Consejo de Estado, Sección Tercera, Subsección C, salvamento parcial de voto formulado a la sentencia del 24 de julio de 2013, exp. 28768.

18 “14B. Competencia de cada Subsección. Cada Subsección decidirá los procesos a su cargo en forma autónoma. Sin embargo, las Subsecciones sesionarán conjuntamente: (...) 3. Para unificar, adoptar o modificar la jurisprudencia de la Sección, con el fin de evitar decisiones contradictorias sobre el mismo punto de derecho, cuando así lo decida la Sección a petición de cualquiera de sus miembros". 
Caducidad de la acción contractual

\subsection{Diferentes tipos de normas jurídicas y su diferencia}

La teoría del derecho, a partir de la discusión introducida por Dorkwin en respuesta a la teoría positivista de L.A. Hart, distingue dentro de las normas jurídicas las reglas de los principios.

Las reglas son normas que exigen un cumplimiento pleno, pues son aplicables o no son aplicables para la solución de un caso específico, es decir, no admite puntos intermedios. Estas, se estructuran por un supuesto de hecho y una consecuencia jurídica, por lo que, si se cumple el supuesto de hecho previsto en la regla, es deber del juez aplicarla, y por el contrario, cuando el supuesto de hecho no se concrete, el juez debe excluir su aplicación ${ }^{19}$.

Los principios, por su parte, no se componen de un supuesto de hecho y una consecuencia jurídica, pues son abstractos. Los principios son considerados mandatos de optimización, toda vez que son "normas que ordenan que algo sea realizado en la mayor medida posible, dentro de las posibilidades jurídicas y reales existentes" 20

A su vez se diferencian en cuanto a la metodología de su aplicación, en razón a que las reglas se emplean mediante la subsunción ${ }^{21}$, mientras que los principios se ponderan ${ }^{22}$.

La subsunción "es una especie de silogismo"23 mediante el cual se compara el caso concreto con la regla jurídica, para determinar si aquel es merecedor

19 BERNAL PULIDO, Carlos. El principio de proporcionalidad y los derechos fundamentales: el principio de proporcionalidad como criterio para determinar el contenido de los derechos fundamentales vinculante para el legislador, $4^{a}$ ed., Bogotá, Universidad Externado de Colombia, 2014, p. 729.

20 ALEXY, Robert. Teoría de los derechos fundamentales. BERNAL PULIDO, Carlos (Traducción), 2a ed., Madrid. Centro de Estudios Políticos y Constitucionales, 2007, pp. 67 y 68.

21 No obstante, hay quienes consideran que esta metodología también es aplicable a los principios, como es el caso de Guastini, quien indica: "De acuerdo con una opinión difundida, la aplicación de las reglas y la aplicación de principios se diferenciarían por lo siguiente: las reglas se aplican mediante la subsunción, mientras que los principios no admiten subsunción. Esta tesis evidencia cuanta ignorancia reina entre los juristas en materia de subsunción": GUASTINI, Riccardo. Nuevos estudios sobre la interpretación. MORENO CRUZ, Diego. (traducción), Bogotá, Universidad Externado de Colombia, 2010, p. 226.

22 CARBONELL, Miguel. El principio de proporcionalidad en el estado constitucional. ALEXY, Robert. La fórmula del peso, Bogotá, Universidad Externado de Colombia, 2007, pp. 15 y 16; PINO. Giorgio. Derechos e interpretación. El razonamiento jurídico en el Estado constitucional. Bogotá, Universidad Externado de Colombia, 2014, p. 147.

23 BERNAL PULIDO, Carlos. El Derecho de los derechos, Bogotá, Universidad Externado de Colombia, 2005, p. 95. 
de la consecuencia jurídica de esta, mientras que la ponderación consiste "en sopesar razones que juegan a favor y en contra de una especifica solución" ${ }^{24}$, la cual se realiza, según Alexy, a través de: la ley de la ponderación, que consiste en establecer la importancia de los principios en colisión y su peso abstracto a partir de la jerarquía de fuente normativa en que estén establecidos; la fórmula del peso, con el cual se establece el peso concreto de los principios en colisión; y finalmente con la carga de argumentación, la cual determina qué principio debe prevalecer en caso de empate al aplicar la fórmula del peso ${ }^{25}$.

En algunos eventos la subsunción es inoperante debido a la inexistencia o indeterminación de la regla o la colisión de estas, caso en el cual el juez se encuentra frente a un caso difícil ${ }^{26}$, y es su deber acudir a los principios para resolver el caso concreto ${ }^{27} \mathrm{o}$ a la introducción de una cláusula de excepción a alguna de las reglas en conflicto $^{28}$.

\subsection{Inexistencia de regla específica para el caso concreto}

Según lo expuesto en el acápite anterior, cabe preguntarse ¿Las normas relativas a la caducidad de las acciones corresponden a reglas o principios? la respuesta indiscutible es que son reglas jurídicas.

En efecto, las normas relativas a la caducidad se componen de un supuesto de hecho -los términos para acudir a la jurisdicción- y de una consecuencia jurídica en caso de no ejercer la acción en dichos lapsos. Siendo esta la imposibilidad de obtener una sentencia de fondo como sanción por su inacción, con el fin de otorgar seguridad jurídica a las relaciones sociales ${ }^{29}$.

$24 \quad$ BERNAL PULIDO, Carlos. El principio de proporcionalidad, Ob. Cit., p. 720.

25 BERNAL PULIDO, Carlos. El neoconstitucionalismo y la normatividad del derecho: escritos de derecho constitucional y filosofía del derecho, Bogotá, Universidad Externado de Colombia, 2009. P. 30 - 33.

26 "Dworkin define los casos difíciles como aquellos en los cuales "un determinado litigio no se puede subsumir claramente en ninguna norma jurídica" o en los que "no existe norma establecida que dicte una decisión en ningún sentido": BERNAL PULIDO, Carlos. El principio de proporcionalidad, Ob. cit., p. 180.

27 Ibidem, p. 729.

28 ALEXY, Robert. Teoría de los derechos fundamentales, Ob. cit., p. 69.

29 "Para nadie es desconocido que la sociedad entera tiene interés en que los procesos y controversias se cierren definitivamente, y que entendiendo ese propósito, se adoptan instituciones y mecanismos que pongan término a la posibilidad de realizar intemporal o indefinidamente actuaciones ante la administración de justicia, para que las partes actúen dentro de ciertos plazos y condiciones, desde luego, con observancia plena de las garantías constitucionales que aseguren amplias y plenas oportunidades de defensa y de contradicción del derecho en litigio": Corte Constitucional, sentencia C - 351 de 1994 
Ahora bien, en relación con el inicio del conteo de la caducidad de la acción contractual, cuando el acto de liquidación es posterior al fenecimiento de las oportunidades legales, la primera consideración es que el juez se encuentra frente a un problema de indeterminación o inexistencia de la regla aplicable.

Por un lado, se encuentra el supuesto usado por la Subsección C según el cual el término de dos años inicia desde el incumplimiento de la obligación de liquidar el contrato luego del vencimiento de las oportunidades bilateral y unilateral para su adopción. Este supuesto está consagrado en la parte final del literal d del artículo 136 del Código Contencioso Administrativo (CCA) y en el numeral v del literal j del artículo 164 del Código de Procedimiento Administrativo y de lo Contencioso Administrativo (CPACA).

En contraste, se encuentran los supuestos que afirman que el término inicia desde la firma del acta cuando sea liquidación bilateral o a partir de la ejecutoria del acta cuando se liquida unilateralmente (literales c y d del artículo 136 del CCA, análogos a los numerales iii y iv del literal J del artículo 164 del CPACA) los cuales sirven de sustento a la segunda de las posturas, es decir, a la defendida por las subsecciones A y B.

Sin embargo, ninguno de los supuestos contemplados en los numerales de los artículos 136 del CCA y 164 del CPACA señala de forma específica desde cuándo empiezan a contarse los dos años de caducidad en caso de que el acto que liquida el contrato sea proferido por fuera de las oportunidades para su adopción bilateral y unilateral.

Es decir, no existe una norma que indique que en caso de que la liquidación del contrato sea posterior a las oportunidades para su adopción bilateral (cuatro meses) y unilateral (dos meses), el término de dos años de caducidad empieza a contarse al fenecer las oportunidades iniciales (seis meses en total) o desde que efectivamente es adoptado, bilateral o unilateralmente. En caso de que dicha norma existiera, el juez estaría frente a un caso fácil y no se presentaría discrepancia entre las subsecciones.

En ese orden de ideas, al no existir una regla concreta y ajustada a la hipótesis en discusión, es imposible que la resolución del caso se realice por medio de la subsunción, toda vez que se otorgaría una consecuencia jurídica a un supuesto de hecho diferente al de la norma ${ }^{30}$.

30 "Es decir, la conducta ha de ser subsumida bajo el supuesto de hecho de la regla pertinente y debe imputarse la consecuencia prevista por esta. Por el contrario, si las condiciones previstas por el supuesto de hecho de una regla no se presentan, esta no debe aplicarse. Solo de esta manera puede entenderse la forma de aplicación "todo o nada". BERNAL PULIDO, Carlos. El principio de proporcionalidad, Ob. cit., p. 734. 
Por ende, el juez se encuentra frente a un caso difícil, que debe ser resuelto por medio del estudio de principios que orienten al juez respecto de la aplicación de una $u$ otra regla ${ }^{31}$.

\subsubsection{Principio de interpretación pro homine y garantía del acceso a la administración de justicia}

El primer principio que debe servir de orientación al juez administrativo para resolver la indeterminación planteada es el de principio de interpretación pro homine o pro persona, según el cual:

"El principio de interpretación <pro homine>, impone aquella interpretación de las normas jurídicas que sea más favorable al hombre y sus derechos, esto es, la prevalencia de aquella interpretación que propenda por el respeto de la dignidad humana y consecuentemente por la protección garantía y promoción de los derechos humanos y de los derechos fundamentales consagrados a nivel constitucional" ${ }^{32}$.

Este principio, que hace parte de nuestro ordenamiento vía bloque de constitucionalidad -por su consagración en el artículo $5^{\circ}$ del Pacto Internacional de Derechos Civiles y Políticos y el artículo 29 de la Convención Americana sobre Derechos Humanos- implica que en el caso concreto se deba preferir la aplicación de la segunda de las posturas expuestas, esto es, la acogida por las Subsecciones A y B, toda vez que es una interpretación garantista.

La inexistencia de una regla específica posiciona al juez frente a la siguiente disyuntiva: aplicar el supuesto según el cual el inicio de la caducidad empieza desde el vencimiento de las oportunidades iniciales para liquidar el contrato bilateral y unilateralmente -lo cual, en la mayoría de los casos deriva en la declaratoria de caducidad de la acción como sanción a la "inacción" del demandante en pro de la seguridad jurídica - o aplicar el supuesto que contabiliza el término desde que efectivamente el acto es adoptado de forma bilateral o desde su ejecutoria si es unilateral, con lo cual permite el estudio del fondo del asunto.

El principio pro homine, como criterio hermenéutico, implica que "el juez debe darle prevalencia a la norma o interpretación que resulte más favorable para la protección de los derechos inalienables de la persona"33 que en el caso

31 De este modo, cuando no existe una regla específica para solucionar un caso dado o cuando la regla pertinente es indeterminada -los casos difíciles-, el juez no se encuentra en una situación en la que pueda tomar una decisión enteramente discrecional. Por el contrario, la decisión debe provenir de la aplicación rigurosa de los principios jurídicos": Ibidem, p. 729.

32 Corte Constitucional, sentencia T-171 de 2009.

33 Corte Constitucional, sentencia T - 522 de 2017 
concreto consiste en inclinarse por la segunda de las posturas, en razón a que los efectos de su aplicación son garantistas del derecho de acceso a la administración de justicia.

El acceso a la administración de justicia se encuentra consagrado en el artículo 229 de la Constitución, según el cual "se garantiza el derecho de toda persona para acceder a la administración de justicia”.

Sobre el alcance de este derecho existen dos tipos de interpretación. Una restringida, que garantiza únicamente el acceso al proceso y a los recursos, y otra que amplía el concepto extendiéndolo además a la obtención de una decisión judicial de fondo y a que esta sea ejecutada ${ }^{34}$.

La Corte Constitucional ha acogido la concepción amplia del acceso a la administración de justicia considerando que una de las manifestaciones de esta garantía es "el derecho a que la promoción de la actividad jurisdiccional concluya con una decisión de fondo en torno a las pretensiones que han sido planteadas" ${ }^{35}$.

De esta forma, la aplicación del principio pro homine al problema planteado le da el verdadero alcance al derecho de acceso a la administración de justicia, pues permite que su ejercicio no sea simplemente formal, sino material. Obteniendo de esta forma una decisión de fondo, la cual, con la interpretación de la subsección C, no sería permitida pues "En tales casos se emite una decisión formalmente denominada sentencia, pero que materialmente no decide el litigio, lo que constituye una flagrante denegación de justicia"36.

Igualmente, contabilizar la caducidad acorde a la interpretación de la Subsección C, impone una carga irracional sobre los demandantes en contravención al acceso a la Administración de justicia, pues sanciona su "inactividad" por no demandar un acto inexistente.

Puede que el contratista, a la terminación del contrato, esté conforme con la ejecución de las prestaciones y considere irrelevante su liquidación, por lo que contar la caducidad a partir del fenecimiento de las oportunidades para liquidarlo, como lo hace la Subsección C, desconoce que el desacuerdo que motiva a acudir a la jurisdicción surge del acto de liquidación.

La posición de la subsección C, de contabilizar la caducidad para demandar un acto desde antes que el mismo exista, va contra la regla general regulada en el

$34 \quad$ TOSCANO, Fredy. Aproximación conceptual al "acceso efectivo a la administración de justicia" a partir de la teoría de la acción procesal, Revista de Derecho Privado № 24, Bogotá, Universidad Externado de Colombia, 2013, p. 252.

35 Corte Constitucional, sentencia C-279 de 2013.

36 TOSCANO, Fredy. Algunas facetas del derecho fundamental al acceso efectivo a la administración de justicia en Colombia. Revista de Derecho Privado N²9, Bogotá, Universidad Externado de Colombia, 2015, pp. 213-232. 
numeral 10 del artículo 136 del CCA y el literal J del artículo 164 del CPACA, y según la cual los dos años de caducidad "se contarán a partir del día siguiente a la ocurrencia de los motivos de hecho o de derecho que les sirvan de fundamento".

La discrepancia surge del acto de liquidación, siendo este el motivo de derecho, por lo que no puede contabilizarse la caducidad desde antes de su existencia, sino desde el día siguiente a su adopción bilateral o unilateral.

\subsubsection{Principio de igualdad}

El principio a la igualdad se erige como uno de los principios fundantes y más importantes dentro de un estado de derecho. En nuestro ordenamiento se encuentra en el artículo 13 de la Constitución y uno de sus mandatos supone "un trato idéntico a destinatarios que se encuentren en circunstancias idénticas" ${ }^{37}$ lo que implica que debe entenderse en términos relacionales ${ }^{38}$ acorde al postulado Aristotélico, según el cual una forma de justicia es tratar igual a los iguales y desigual a los desiguales.

A partir de la anterior formulación, la Corte Constitucional ha configurado un test de igualdad, con el fin de contrastar las situaciones y poder determinar si existe vulneración de tal derecho. Los componentes y elementos del test de igualdad son:

(i) La existencia de grupos o personas comparables, esto es que se encuentren en iguales circunstancias o en situaciones donde las semejanzas son más relevantes que las diferencias; (ii) la existencia fáctica de un tratamiento desigual y la materia sobre la cual recae; (iii) la existencia de un objetivo perseguido a través del establecimiento del trato desigual; (iv) la validez del objetivo a la luz de la Constitución y, (v) la proporcionalidad entre el trato desigual y el fin perseguido ${ }^{39}$.

37 BERNAL PULIDO, Carlos. El Derecho de los derechos, Ob. cit., p. 257.

38 "El principio de igualdad posee un carácter relacional, lo que significa que deben establecerse dos grupos o situaciones de hecho susceptibles de ser contrastadas, antes de iniciar un examen de adecuación entre las normas legales y ese principio. Además, debe determinarse si esos grupos o situaciones se encuentran en situación de igualdad o desigualdad desde un punto de vista fáctico, para esclarecer si el Legislador debía aplicar idénticas consecuencias normativas, o si se hallaba facultado para dar un trato distinto a ambos grupos; en tercer término, debe definirse un criterio de comparación que permita analizar esas diferencias o similitudes fácticas a la luz del sistema normativo vigente; $\mathrm{y}$, finalmente, debe constatarse si se presenta un tratamiento distinto entre iguales (o igual entre desiguales) y si este resulta razonable. Es decir, si persigue un fin constitucionalmente legítimo y no restringe en exceso los derechos de uno de los grupos en comparación.": Corte Constitucional, sentencia C-006 de 2017.

39 Corte Constitucional, sentencia T-971 de 2009. 
Si se aplicara el anterior test a las interpretaciones coexistentes frente a la contabilización del término de caducidad, se consideraría:

i) Existen grupos de personas comparables, siendo estos quienes acuden a la jurisdicción contencioso administrativa en ejercicio de la acción contractual;

ii) Fácticamente se presenta un trato desigual, en razón a que hay dos grupos de sujetos: los primeros a quienes la Subsección C decide declarar la caducidad de la acción y por otra parte quienes las otras subsecciones estudian de fondo sus demandas;

iii) El trato desigual persigue un objetivo admisible que es el "respeto" por los términos señalados en la ley para el ejercicio de la acción contractual y el instituto de la caducidad que es de orden público;

iv) Pese a que la postura de la Subsección C persigue un fin loable, no es adecuada debido a que coloca los accionantes en desventaja respecto de quienes en la misma situación son juzgados de forma menos rigurosa, obteniendo estos un fallo de fondo;

v) En cuanto a la proporcionalidad entre el trato desigual y el fin perseguido, se concluye que el conteo de la caducidad de la acción a partir de una tesis restringida, no es proporcional, pues se transgreden derechos fundamentales como lo es el derecho a la igualdad y acceso a la administración de justicia, como ya se explicó.

No puede considerarse que las sentencias que declaran la caducidad desconozcan un precedente horizontal, debido a la ausencia de jurisprudencia unificada sobre la materia dentro de la Sección Tercera del Consejo de Estado. Sin embargo, sí se considera que incurren en violación directa de la constitución por desconocimiento de un precepto constitucional (derecho a la igualdad $)^{40}$.

\subsection{Indebida interpretación y aplicación de la regla jurídica}

La balanza se inclina a favor de la segunda de las tesis, no solo bajo las consideraciones expuestas a la luz de los principios pro homine y de igualdad. A la misma conclusión se arribaría, si se hace un estudio detallado de la regla

40 En sentencia T - 102 de 2014 la Corte Constitucional declaró la existencia de defecto fáctico por violación directa de un precepto constitucional (derecho a la igualdad), respecto de una sentencia de la Subsección C de la Sección Tercera del Consejo de Estado en la que utilizó el test de proporcionalidad a la hora de liquidar los perjuicios inmateriales, toda vez que este es un "método que no está avalado ni es utilizado en otras decisiones adoptadas por la misma autoridad judicial accionada, lo cual constituye una vulneración al derecho a la igualdad de los peticionarios". 
jurídica empleada por la Subsección C, toda vez que, a mi juicio, dicha regla no es la aplicable para resolver la controversia; por lo que al eliminarla -de la posibilidad de aplicación ${ }^{41}$ - el juez únicamente puede echar mano de la regla que contabiliza la caducidad desde que se suscribe el acta o desde la ejecutoria del acto de liquidación unilateral, según sea el caso.

Para desechar el supuesto usado por la subsección C es necesario interpretar el mismo antes de aplicarlo, pues estos dos -interpretación y aplicación- son escenarios diferentes pero necesarios al momento de resolver un caso concreto ${ }^{42}$.

Con la anterior finalidad, es menester hacer un estudio cronológico y sistemático de la norma relativa a la caducidad de la acción contractual desde el Código Contencioso Administrativo (Decreto 01 de 1984) hasta lo que consagra al respecto el Código de Procedimiento Administrativo y de lo Contencioso Administrativo (Ley 1437 de 2011).

El artículo 136 original del Decreto 01 de 1984 señalaba que los dos años de caducidad de la acción de controversias contractuales comenzaban a partir de "expedidos los actos u ocurridos los hechos que den lugar a ella". Posteriormente con la modificación introducida por el Decreto 2304 de 1989 se indicó que iniciaban una vez "ocurridos los motivos de hecho o de derecho que le sirvan de fundamento".

Sin embargo, estas normas se quedaron cortas respecto a las diferentes controversias suscitadas con ocasión de un contrato estatal, por lo que la jurisprudencia suplió tales vacíos señalando:

En materia contractual habrá que distinguir los negocios que requieren de una etapa posterior a su vigencia para liquidarlos, de aquellos otros que

${ }_{41} \quad$ "Una situación de conflicto se presenta cuando en un mismo sistema jurídico existen dos normas que tienen la misma jerarquía, datan de la misma época, tienen la misma generalidad o especialidad y establecen deberes jurídicos contradictorios entre sí. Cuando se presenta un conflicto entre reglas, una de las cuales no puede ser declarada inválida según los criterios de jerarquía, posterioridad y especialidad, solo puede ser solucionado mediante la introducción a una de las reglas de una cláusula de excepción. De conformidad con esta cláusula de excepción, la regla ha de aplicarse siempre, a excepción de los casos que caigan bajo el supuesto de hecho prescrito por la regla contraria, en los cuales será esta ultima la que determinará la solución": BERNAL PULIDO, Carlos. El principio de proporcionalidad, Ob. cit., pp. 724 y 735.

42 "En lo que se refiere al discurso de los jueces es necesario distinguir al menos entre interpretación y aplicación. Se interpretan textos normativos, se aplican normas (o, si así se quiere decir, textos normativos interpretados). Interpretar es decidir cuál es el significado de un texto normativo, de modo tal que se obtenga una o más normas. Aplicar las normas así obtenidas es utilizarlas para resolver controversias concretas": GUASTINI, Riccardo. Nuevos estudios sobre la interpretación. MORENO CRUZ, Diego. (traducción), Bogotá, Universidad Externado de Colombia, 2010, p. 225. 
no necesitan de la misma. En éstos, vale decir, para los cuales no hay etapa posterior a su extinción, cualquier reclamación judicial deberá llevarse a cabo dentro de los dos años siguientes a su fenecimiento. Para los contratos, respecto a los cuales se impone el trámite adicional de liquidación, dicho bienio para accionar judicialmente comenzará a contarse desde cuando se concluya el trabajo de liquidación, o desde cuando se agotó el término para liquidarlo sin que se hubiere efectuado, bien sea de manera conjunta por las partes o unilateralmente por la administración ${ }^{43}$.

Igual a como ocurrió con las oportunidades para liquidar el contrato, posteriormente el legislador positivizó tales criterios jurisprudenciales y en el artículo 44 de la Ley 446 de 1998, modificatorio del 136, indicó:

10. En las relativas a contratos, el término de caducidad será de dos (2) años que se contará a partir del día siguiente a la ocurrencia de los motivos de hecho o de derecho que les sirvan de fundamento.

En los siguientes contratos, el término de caducidad se contará así:

a) En los de ejecución instantánea, a más tardar dentro de los dos (2) años siguientes a cuando se cumplió o debió cumplirse el objeto del contrato;

b) En los que no requieran de liquidación, a más tardar dentro de los dos (2) años siguientes, contados desde la terminación del contrato por cualquier causa;

c) En los que requieran de liquidación y ésta sea efectuada de común acuerdo por las partes, a más tardar dentro de los dos (2) años, contados desde la firma del acta;

d) En los que requieran de liquidación y ésta sea efectuada unilateralmente por la administración, a más tardar dentro de los dos (2) años, contados desde la ejecutoria del acto que la apruebe. Si la administración no lo liquidare durante los dos (2) meses siguientes al vencimiento del plazo convenido por las partes o, en su defecto del establecido por la ley, el interesado podrá acudir a la jurisdicción para obtener la liquidación en sede judicial a más tardar dentro de los dos (2) años siguientes al incumplimiento de la obligación de liquidar;

e) La nulidad absoluta del contrato podrá ser alegada por las partes contratantes, por el Ministerio Público o cualquier persona interesada, dentro de los dos (2) años siguientes a su perfeccionamiento. Si el término de vigencia del contrato fuere superior a dos (2) años, el término de caducidad será igual al de su vigencia, sin que en ningún caso exceda de cinco (5) años,

43 Consejo de Estado, Sala de lo Contencioso Administrativo, Sección Tercera, sentencia del 22 de junio de 1995, exp. 9965. 
contados a partir de su perfeccionamiento. En ejercicio de esta acción se dará estricto cumplimiento al artículo 22 de la Ley "por la cual se adoptan como legislación permanente algunas normas del Decreto 2651 de 1991, se modifican algunas del Código de Procedimiento Civil, se derogan otras de la Ley 23 de 1991 y del Decreto 2279 de 1989, se modifican y expiden normas del Código Contencioso Administrativo y se dictan otras disposiciones sobre descongestión, eficiencia y acceso a la justicia. (énfasis del autor)

El literal d) del numeral 10 del artículo 44 de la Ley 446 de 1998 transcrito, el cual ha servido de fundamento a la subsección $\mathrm{C}$ para declarar la caducidad, se refiere a dos supuestos diferentes: i) el primero relativo a la contabilización de la caducidad cuando la liquidación es efectuada unilateralmente, y la cual empieza a partir de la ejecutoria del acto que la apruebe; ii) el segundo supuesto se refiere a la contabilización del término cuando el contrato no se liquida luego de la oportunidad bilateral y unilateral para ello $(4+2)$, e inicia a partir del vencimiento de dichos plazos.

Es decir, el entendimiento de la Subsección C es correcto, pues al vencimiento de las oportunidades para la liquidación bilateral y unilateral inicia el conteo de la caducidad de la acción. Sin embargo, pasa por alto que la caducidad de la segunda parte del inciso d) del numeral 10 del artículo 44 de la Ley 446 de 1998, modificatorio del 136 del CCA, se refiere solamente a un tipo de pretensión, siendo esta la relativa a la liquidación judicial del contrato ${ }^{44}$.

Lo anterior encuentra sustento si se observa como en primer lugar el CPACA, dividió los supuestos en el literal J del numeral 2 de su artículo 164:

Artículo 164. [...]

iv) En los que requieran de liquidación y esta sea efectuada unilateralmente por la administración, desde el día siguiente al de la ejecutoria del acto administrativo que la apruebe;

v) En los que requieran de liquidación y esta no se logre por mutuo acuerdo o no se practique por la administración unilateralmente, una vez cumplido el término de dos (2) meses contados a partir del vencimiento del plazo convenido para hacerlo bilateralmente o, en su defecto, del término de los cuatro (4) meses siguientes a la terminación del contrato o la expedición del acto que lo ordene o del acuerdo que la disponga; [...]

Además, este último numeral debe ser contrastado con el artículo 141 del mismo cuerpo normativo que preceptúa: "Así mismo, el interesado podrá solicitar la liquidación judicial del contrato cuando esta no se haya logrado de

44 "el interesado podrá acudir a la jurisdicción para obtener la liquidación en sede judicial". 
mutuo acuerdo y la entidad estatal no lo haya liquidado unilateralmente dentro de los dos (2) meses siguientes al vencimiento del plazo convenido para liquidar de mutuo acuerdo o, en su defecto, del término establecido por la ley". Es decir, se reiteró que en dicho supuesto la caducidad que se cuenta es la de la pretensión relativa a la liquidación judicial del contrato, más no de la pretensión dirigida a atacar el contenido del acto de liquidación.

La acción de controversias contractuales es pluripretensional ${ }^{45}$, y el legislador decidió que la caducidad de la pretensión relativa a la liquidación judicial del mismo iniciará una vez se incumplieran los términos de la liquidación bilateral o unilateral, por lo que no puede extenderse dicho inicio a cuando el acto se liquida por fuera de las oportunidades iniciales.

Así las cosas, la regla bajo la cual sustenta su posición la Subsección C no puede ser aplicada y, por el contrario, debe ser excluida por el juez, en razón a que regula un supuesto de hecho diferente a la hipótesis en discusión. Por ende, al excluirse dicha regla, únicamente puede resolverse la controversia según lo señalado en el literal c) o la parte inicial del d) del numeral 10 del artículo 136 del CCA o los numerales iii) y iv) del literal j del numeral 2 del artículo 164 del CPACA, dependiendo de si la liquidación fue bilateral o unilateral.

\subsection{El acto de liquidación es un acto contractual}

Dentro de los actos proferidos con ocasión de la actividad contractual de la administración, se diferencian los que se producen en la etapa precontractual de aquellos que son proferidos con ocasión de la celebración del contrato.

Los primeros han sido denominados actos separables del contrato y se refiere a los producidos desde la apertura del proceso de selección hasta la celebración del contrato. En relación con estos, el legislador estableció un régimen especial debido a que son autónomos respecto del contrato y por ende el control de legalidad de estos se ejerce mediante acciones o medios de control distintos a los propios de las controversias contractuales ${ }^{46}$.

45 "La de controversias contractuales, de conformidad con lo preceptuado por el artículo 87 del Código Contencioso Administrativo, no es una acción instituida con un contenido normativo o con un propósito único, comoquiera que la disposición en comento deja claro que se trata de una vía procesal de naturaleza pluripretensional, esto es, que bajo su égida pueden ser planteadas al juez toda la variedad de situaciones problemáticas que pueden tener lugar en el ámbito de las relaciones contractuales de las entidades estatales; a ese respecto se ha pronunciado la Sección Tercera de esta Corporación": Consejo de Estado, Sala de lo Contencioso Administrativo, Sección Tercera, Subsección A, sentencia del $1^{\circ}$ de agosto de 2016, exp. 35721.

46 SANTOS, Jennifer. La teoría de los actos separables del contrato estatal: distinción a la Ley 1437 de 2011. Revista Academia y Derecho Nº 17, Cúcuta, Universidad Libre, 2013, p. 136. 
En efecto, el original del artículo 87 del Decreto 01 de 1984 indicaba que "los actos separables del contrato serán controlables por medio de las otras acciones previstas en este Código". Posteriormente con la modificación introducida por la Ley 446 de 1998 en su artículo 32, se señaló que "Los actos proferidos antes de la celebración del contrato, con ocasión de la actividad contractual, serán demandables mediante las acciones de nulidad y nulidad y restablecimiento del derecho, según el caso dentro de los treinta días siguientes a su comunicación, notificación o publicación. La interposición de estas acciones no interrumpirá el proceso licitatorio, ni la celebración y ejecución del contrato. Una vez celebrado éste, la ilegalidad de los actos previos solamente podrá invocarse como fundamento de nulidad absoluta del contrato".

Igualmente, el CPACA continúo con esta línea de pensamiento y en el inciso $2^{\circ}$ del artículo 141 consagró "Los actos proferidos antes de la celebración del contrato, con ocasión de la actividad contractual, podrán demandarse en los términos de los artículos 137 y 138 de este Código, según el caso". Estos últimos artículos relativos a los medios de control de nulidad y nulidad y restablecimiento del derecho, y que según el literal c) del numeral 2 del artículo 164 ibidem deben ejercerse en un término de 4 meses a partir del día siguiente a su comunicación, notificación, ejecución o publicación.

Como se puede evidenciar, el legislador únicamente avaló la impugnación de los actos proferidos en la etapa precontractual -actos separables del contratoa través de una acción diferente de la contractual. La impugnación de los demás actos debe hacerse en uso de la acción de controversias contractuales acorde a lo señalado en el artículo 77 de la Ley 80 de $1993^{47}$.

Así las cosas, la única vía para atacar el acto de liquidación es por medio de la acción contractual, toda vez que es un acto contractual ${ }^{48}$ proferido en la etapa postcontractual.

Por ende, considero errado que la subsección $C$ señale que si el acto es proferido por fuera de los dos años posteriores a las oportunidades para liquidar el contrato, bilateral o unilateral, la acción a impetrar contra este es la de nulidad y restablecimiento del derecho y que caduca a los 4 meses. Siendo únicamente procedente, a mi juicio, atacarlo a través de la acción contractual dentro del término de dos años conforme se ha defendido a lo largo de este escrito.

\footnotetext{
47 "Los actos administrativos que se produzcan con motivo u ocasión de la actividad contractual sólo serán susceptibles de recurso de reposición y del ejercicio de la acción contractual (...)" (énfasis del autor).

48 BENAVIDES, José Luis. El contrato estatal, entre el Derecho público y el Derecho privado, $2^{\text {a }}$ ed., Bogotá, Universidad Externado de Colombia, 2010, p. 406.
} 
Caducidad de la acción contractual

\section{Conclusión}

Actualmente en la Sección Tercera del Consejo de Estado subsisten dos posiciones con relación al cómputo de la caducidad de la acción de controversias contractuales cuando el acto de liquidación se profiere por fuera de las oportunidades para su adopción bilateral o unilateral.

Una de las posiciones (Subsección C) es restrictiva y contabiliza la caducidad desde que se incumple la obligación de liquidar el contrato bilateral o unilateralmente. Esta, además considera que la acción que se ha de ejercer contra el acto de liquidación es la de nulidad y restablecimiento del derecho si este se profiere luego de los dos años de caducidad. La segunda posición (Subsecciones A y B) contabiliza la caducidad desde la firma del acta o desde la ejecutoria del acto, dependiendo si es bilateral o unilateral.

Los efectos de la aplicación de una u otra postura frente a un caso concreto son totalmente diversos, pues bajo la primera posición se declara la caducidad de la acción, mientras que con la segunda se permite el estudio del fondo de la controversia.

La coexistencia de las dos tesis es reprochable, no solo por las diversas consecuencias que genera la adopción de una u otra postura, sino igualmente porque va en contravía con la finalidad del Consejo de Estado como órgano de cierre de la Jurisdicción Contencioso Administrativa, e incentiva perversamente que se ponga en movimiento el aparato jurisdiccional, con ocasión de eventuales acciones de tutela.

Es necesario que la Sección Tercera unifique su jurisprudencia para evitar fallos contradictorios y garantizar la igualdad de quienes acuden a la jurisdicción, y con tal fin se sugiere que se incline a favor de la segunda de las tesis.

En el presente trabajo se logró demostrar que el estudio de la controversia acorde a principios como el de interpretación pro homine e igualdad, implica que la tesis de la subsección $C$ sea rebatida por restringir el acceso a la administración de justicia y vulnerar el derecho a la igualdad.

Además, la interpretación de la norma que sirve de fundamento a la subsección $\mathrm{C}$ para hincar su tesis, demuestra que el inicio del término de caducidad una vez se incumplen las oportunidades para la liquidación del contrato, se restringió a la pretensión de liquidación judicial.

Finalmente, se dan las razones por las cuales la acción para impugnar el acto de liquidación siempre es la de controversias contractuales, con lo que se rebate el argumento que sugiere que en determinadas circunstancias debe atacarse en uso de la acción de nulidad y restablecimiento del derecho. 


\section{Bibliografía}

ALEXY, ROBERT. Teoría de los derechos fundamentales. BERNAL PULIDO, CARLOS (Traducción), $2^{\text {a }}$ ed., Madrid, Centro de Estudios Políticos y Constitucionales, 2007.

BENAVIDES, JOSE LUIS. El contrato estatal, entre el Derecho público y el Derecho privado, $2^{\text {a }}$ ed., Bogotá, Universidad Externado de Colombia, 2010.

BERNAL PULIDO, CARLOS. El Derecho de los derechos, Bogotá, Universidad Externado de Colombia, 2005.

BERNAL PULIDO, CARLOS. El neoconstitucionalismo y la normatividad del derecho: escritos de derecho constitucional y filosofía del derecho, Bogotá, Universidad Externado de Colombia, 2009.

BERNAL PULIDO, CARLOS. El principio de la proporcionalidad y los derechos fundamentales: el principio de proporcionalidad como criterio para determinar el contenido de los derechos fundamentales vinculante para el legislador. $4^{a}$ ed., Bogotá, Universidad Externado de Colombia, 2014.

CARBONELL, MIGUEL. El principio de proporcionalidad en el estado constitucional. ALEXY, Robert. La fórmula del peso. Bogotá, Universidad Externado de Colombia, 2007.

EXPÓSITO, JUAN CARLOS. La liquidación bilateral de los contratos estatales: un mecanismo alternativo de solución de conflictos, Revista digital de derecho administrativo $\mathrm{N}^{\circ}$ 1, Bogotá, Universidad Externado de Colombia, 2009.

GALINDO VACHA, JUAN CARLOS. Lecciones de derecho procesal administrativo, Vol 2, Bogotá, Pontificia Universidad Javeriana, 2006.

GUASTINI, RICCARDO. Nuevos estudios sobre la interpretación. MORENO CRUZ, DIEGO. (traducción), Bogotá, Universidad Externado de Colombia, 2010.

HERNÁNDEZ, AIDA PATRICIA. La liquidación del contrato estatal, Bogotá, Revista digital de derecho administrativo $\mathrm{N}^{\circ} 1$, Universidad Externado de Colombia, 2009.

LÓPEZ, HERNAN FABIO. Procedimiento civil, Parte General, Tomo I, 9. ${ }^{a}$ ed., Bogotá, Dupré editores, 2005.

PALACIO, JUAN ANGEL. Derecho procesal administrativo, 9. ed., Bogotá, Librería Jurídica Sánchez R Ltda, 2017.

PINO, GIORGIO. Derechos e interpretación. El razonamiento jurídico en el Estado constitucional. Bogotá, Universidad Externado de Colombia, 2014. 
SANTOS, JENNIFER PATRICIA. La teoría de los actos separables del contrato estatal: distinción a la Ley 1437 de 2011, Revista Academia y derecho N 17, Cúcuta, Universidad Libre, 2013.

TOSCANO, FREDY. Algunas facetas del derecho fundamental al acceso efectivo a la administración de justicia en Colombia, Revista de Derecho Privado N²9, Bogotá, Universidad Externado de Colombia, 2015.

TOSCANO, FREDY. Aproximación conceptual al "acceso efectivo a la administración de justicia" a partir de la teoría de la acción procesal, Revista de Derecho Privado N. ${ }^{\circ}$ 24, Bogotá, Universidad Externado de Colombia, 2013. 